Rev, Elev. Méd. vét. Pays trop., 1973, 26 (4) : 71 a - 74 a

\title{
La peste des petits ruminants (PPR) et sa prophylaxie au Sénégal et en Afrique de l'ouest
}

\author{
par P. BOURDIN (*)
}

\begin{abstract}
RESUME
La peste des petits ruminants est une maladie bien connue dans les pays de l'Ouest africain. Elle atteint surtout les caprins; après un rappel sur les principaux vaccins utilisés pour lutter contre cette affection, il est fait état des expérimentations sur l'efficacité du vaccin utilisé pour lutter contre la peste bovine et préparé sur culture cellulaire; le choix de ce vaccin étant guidé par la facilité de sa préparation et son innocuité pour les chèvres. Si les résultats expérimentaux n'ont pas toujours été concluants, les résultats sur le terrain sont satisfaisants. L'appréciation de l'état immunitaire acquis ou naturel par le titrage des anticorps neutralisant le virus de la peste bovine pose des problèmes d'ordre immunologique.
\end{abstract}

\section{GENERALITES ET ANCIENS ESSAIS DE PROPHYLAXIE DE LA PPR}

La Peste des Petits Ruminants (PPR) existe à l'état endémique dans l'Afrique de l'Ouest, principalement dans les régions à climat de type tropical. Elle est bien individualisée au Dahomey, au Togo, dans le sud du Nigeria et en Côte d'Ivoire (4). Dans ces pays vivent des petits ruminants caractérisés par leur format réduit, appartenant à la race dite " des lagunes " ou " guinéenne ", particulièrement sensibles à la $\mathbf{P P R}$.

Dans les pays sahéliens, et notamment au Sénégal où vivent des petits ruminants de race dite "sahélienne" (sauf au Sénégal oriental où se trouve un petit noyau d'animaux guinéens), la PPR sévit de manière épisodique. On la rencontre surtout durant la saison fraîche en zone arachidière. A cette époque, l'abaissement de la température nocturne et le mouvement des troupeaux des zones d'élevage vers les régions agricoles favorisent son extension. Dans ces pays la maladie est, sauf dans de très rares exceptions, observée uniquement chez des caprins sahéliens.

Le virus responsable de la PPR appartient à la famille des paramyxoviridae, sous-groupe MRD. Sa morphologie, ses propriétés physico-chimiques, biologiques et antigéniques sont très étroitement liées à celles du virus de la peste bovine (P.B.). Il provoque surtout chez les caprins et plus rarement chez les ovins une maladie contagieuse caractérisée par un profond état typhique avec une atteinte du système réticulo-endothélial, et des muqueuses digestives et respiratoires. La contagion est essentiellement directe et la pénétration du virus se fait au niveau des voies respiratoires supérieures sous la forme de très fines gouttelettes.

Le virus est dénué de pouvoir pathogène pour les bovins; inoculé chez ceux-ci par la voie veineuse, il ne provoque aucune réaction clinique visible et n'est pas retrouvé dans le mucus nasal, contrairement à ce qui se passe pour la chèvre, MORNET, ORUE, GILBERT et collab.

$\left(^{*}\right)$ I.E.M.V.T., Laboratoire National de l'Elevage, B.P. $n^{\circ}$ 2057, Dakar-Hann, Sénégal. 
(1956) (10), GILBERT et MONNIER (1962) (5), BOURDIN et LAURENT (1967) (2), LAURENT (1968) (7) pensent que le virus PPR est un mutant du virus P.B. très pathogène pour les caprins, devenu avirulent pour les bovins.

Compte tenu de ces propriétés, les chercheurs ont expérimenté, pour la prophylaxie médicale de la maladie, les vaccins habituellement utilisés pour lutter contre la peste bovine, en attendant de disposer d'un virus PPR suffisamment atténué.

En 1942, GARGADENNEC et LALANNE (4) essayent en vain le virus P.B. inactivé par le formol. En 1956, MORNET, ORUE, GILBERT et collab. (10) après une tentative infructueuse avec le virus PPR inactivé, lui substituent le virus lapinisé qui, du reste, a été utilisé sur le terrain en Côte d'Ivoire. En 1962, GLLBERT et MONNIER (5) adaptent le virus PPR aux cellules épithéliales de rein de fotus de mouton et l'atténuent par des passages en série (1963-64) (6). Malheureusement, les essais de vaccination ne sont pas concluants et la production du vaccin homologue sur cellules de mouton se heurte à des difficultés techniques.

\section{RECHERCHES ACTUELLES}

Pour ces raisons, BOURDIN, RIOCHE et LAURENT (1969-70) (3) songent à expérimenter le virus bovipestique adapté par PLOWRIGHT et FERRIS (1962) (11) aux cellules rénales de fotus de veau. Ils utilisent la souche RP KO/BK qui a subi 65 passages. Cette souche a été jusqu'à présent très largement utilisée en Afrique de l'Ouest pour la prophylaxie de la peste bovine.

\section{Recherches en laboratoire}

Les premières expériences débutent au Dahomey où malheureusement elles ne sont pas toujours démonstratives en raison, d'une part de la difficulté à trouver sur les marchés des animaux non contaminés et, d'autre part, des mauvaises conditions d'habitat auxquelles les chèvres sont très sensibles.

Un mois plus tard, des essais parallèles sont faits à Dakar sur des caprins guinéens non contaminés, acquis dans la région du Sénégal Oriental. Le soutien logistique trouvé sur place permet de maintenir les animaux à des conditions d'hygiène et d'alimentation correctes.

Soixante-quinze chèvres de race guinéenne sont vaccinées avec le virus RP KO/BK 65 passages; chaque animal reçoit environ 5000 DI 50 CT par la voie sous-cutanée au niveau de l'encolure. Dans les jours qui suivent, la température est prise quotidiennement et il n'est relevé aucune réaction locale ou générale.

L'efficacité de cette vaccination est ensuite vérifiée en injectant par voie sous-cutanée à des intervalles de temps différents $5000 \mathrm{DI} 50 \mathrm{CT}$ d'une souche virulente de PPR ramenée du Dahomey, immatriculée " $45 \mathrm{G}$ ), dont le pouvoir pathogène est en même temps contrôlé sur animaux témoins.

Dans un premier temps, 5 animaux sont éprouvés 15 jours après la vaccination. Aucune modification de l'état général ne se manifeste.

Puis quarante chèvres subissent la même épreuve le $21^{\mathrm{e}}$ jour; parmi elles, deux sujets meurent de PPR et le diagnostic est confirmé par précipito-diffusion et isolement du virus. Les autres chèvres ne manifestent rien de particulier.

Enfin, les 30 dernières chèvres éprouvées le $60^{\mathrm{e}}$ jour supportent parfaitement l'inoculation de la souche virulente. Tous les témoins font une maladie typique et il est facile de confirmer le diagnostic clinique par les examens de laboratoire. 


\section{Essais sur le terrain}

Ces travaux expérimentaux sont immédiatement complétés par des essais sur le terrain. Dès 1969, au Dahomey, avec le concours des agents de l'Elevage, il est possible de vacciner des effectifs entiers d'animaux des lagunes dans les régions où, habituellement, la maladie sévit très régulièrement. Une enquête faite en 1970 permet d'apprécier les résultats obtenus. Les agents de l'Elevage ont immunisé 20000 petits ruminants dans des cantons, des villages ou des villes situés dans des zones traditionnellement touchées par la PPR. Dans ces zones, début 1970, éclate une nouvelle flambée de PPR. Les agents chargés de la protection sanitaire du cheptel sont unanimes à reconnaître que les animaux vaccinés et les caprins en particulier, ne sont pas touchés par la maladie, tandis qu'elle sévit dans les effectifs que les éleveurs avaient, soit par négligence, soit par méfiance, refusé de vacciner.

L'utilisation au Sénégal du vaccin directement dans plusieurs foyers de PPR, en 1970 et 1971 , permet de limiter les pertes à 20 p. 100 tandis qu'elles restent élevées dans un foyer laissé comme témoin. Début 1971, dans un village près de Thiès bien séparé en deux parties, les caprins de la partie sud sont tous vaccinés. Quelques mois plus tard, la PPR touche la partie nord et reste inconnue dans la partie sud. Au cours d'une visite dans ce village en 1972, les éleveurs ont spontanément demandé la vaccination de tous les jeunes animaux.

\section{REMARQUES ET CONCLUSIONS}

Les recherches sur la prophylaxie médicale de la PPR faisaient l'objet d'une convention signée avec le Gouvernement du Dahomey, d'une durée limitée à 1 an. Il était primordial de prouver sur le terrain la validité et l'utilité de la vaccination pour prendre ensuite en considération les problèmes apparus au cours de l'expérimentation, notamment des problèmes d'ordre immunologique.

Les recherches sur la vaccination ont entraîné de nombreux contrôles sérologiques. Ces contrôles avaient pour objet la mise en évidence des anticorps neutralisant le virus de la peste bovine dans le sérum des petits ruminants. Au départ, on admettait qu'en raison des étroites relations antigéniques existant entre les virus $\mathrm{PB}$ et PPR, la présence d'anticorps neutralisant le virus PB pouvait signifier que l'animal était résistant vis-à-vis de la PPR. Les examens sérologiques sont faits par la méthode cinétique (1); les dilutions finales des sérums sont comprises, pour chaque sérum, entre le $1 / 10$ et le $1 / 80$. Le système révélateur est la lignée cellulaire de rein de bovin adulte mise au point par MADIN et DARBY (1958) (9). Pour la grande majorité, les examens concernent des sérums de caprins guinéens ou sahéliens, prélevés avant et après vaccination, ou avant l'infection expérimentale réalisée soit par inoculation, soit par mise en contact avec un individu cliniquement malade.

Pour les chèvres infectées expérimentalement, quelle que soit la race, la présence d'anticorps neutralisant le virus $P B$ au $1 / 10$ et au $1 / 20$ et même dans 50 p. 100 des cas au 1/40 n'est pas concomitante d'un état de résistance à la PPR. Par la suite, quand le virus PPR a pu être adapté à la lignée MDBKC (LAURENT, 1971), l'examen des sérums dans des conditions similaires a montré la présence d'anticorps neutralisant le virus PPR à des titres identiques à ceux trouvés pour le virus P.B. L'origine de ses anticorps est encore inconnue.

\section{SUMMARY \\ Pseudo rinderpest : Prevention by vaccination in Senegal and West Africa}

Pseudo rinderpest of sheep and goats is a well known viral disease in countries of Western. Africa. The affection concern chiefly caprine. After a brief review of the principal vaccins utilized to cope with the disease, the authors report the results of experiments carried out in the 
laboratory of Dakar on the efficiency of the rinderpest cell culture vaccine. This vaccine was chosed for the following various reasons: close relationship between PPR and rinderpest viruses, the easy preparation and the harmlessness for the goats.

If the results of experimental trial can be discussed, the vaccination in the field presented a great amount of interest.

The study of natural or artificially developped immunity carried on by the titration of neutralizing antibodies involved immunological problems to be solved.

\section{RESUMEN}

La peste de los pequeños rumiantes y su profilaxia en Senegal y en Africa del oeste

La peste de los pequeños rumiantes es una enfermedad muy conocida en los paises de Africa del oeste. Sobretodo ataca los cabrunos; Después de recordar las principales vacunas utilizadas para luchar contra dicho enfermedad, el autor indica las experimentaciones hechas sobre la eficacia de la vacuna utilizada contra la peste bovina y preparada sobre cultivo celular.

Se escoge esta vacuna por causa de la facilidad de su preparación y de su inocuidad para las cabras.

Los resultados experimentales no han sido siempre concluyentes sino los resultados sobre terreno son satisfactorios. La apreciacion del estado inmunitario adquirido o natural por el dosaje de los anticuerpos neutralizando el virus de la peste bovina plantea problemas de orden inmunologico.

\section{BIBLIOGRAPHIE}

1. BOURDIN (P.) et BERNARD (G.). Application de la méthode de séro-neutralisation cinétique à la recherche des anticorps neutralisant le virus de la peste bovine chez les bovins, les caprins et les ovins. Rev. Elev. Méd. vét. Pays trop., 1967, 20 (4): 531-535.

2. BOURDIN (P.) et LAURENT (A.). Note sur la structure du virus de la peste des petits ruminants. Rev. Elev. Méd. vét. Pays trop., 1967, 20 (3) : 383-386.

3. BOURDIN (P.), RIOCHE (M.) et LAURENT (A.). Etude de la peste des petits ruminants. Travail exécuté à la demande du Gouvernement de la République du Dahomey. Rapport fínal, 1969.

4. GARGADENNEC (L.) et LALANNE (A.). La peste des petits ruminants. Bull. Servs. zootech. Epizoot. A.O.F., 1942, 5 (1) : 16-21.

5. GILBERT (Y.). et MONNIER (J.). Adaptation du virus de la PPR aux cultures cellulaires. Rev. Elev. Méd. vét. Pays trop., 1962, 15 (4): 321-335.

6. GILBERT (Y.) et MONNIER (J.). Rapport annuel du Laboratoire national de Recherches vétérinaires de Dakar, 1963-64.

7. LAURENT (A.). Aspects biologiques de la multiplication du virus de la peste des petits ruminants sur les cultures cellulaires. Rev. Elev. Méd. vét. Pays trop., 1968, 21 (3) : 297-308.

8. LAURENT (A.). Observations personnelles (non publiées), 1969.

9. MADIN (S. H.) et DARBY (N. D.). Established kidney cell lines of normal adult bovine and ovine origin. Proc. Soc. Exp. Biol. Med., 1958, 98: 574-576.

10. MORNET (P.), ORUE (J.), GILBERT (Y.), THIERY (G.) et SAW (M.), La peste des petits ruminants en Afrique occidentale française. Ses rapports avec la peste bovine. Rev. Elev. Méd. vét. Pays trop., 1956,9 (4) : 313-342.

11. PLOWRIGHT (W.) et FERRIS (R. D.). Studies with rinderpest virus in tissue culture. The use of attenuated culture virus as a vaccine for cattle. Res. ver. Sci., 1962, 8: 172-182. 